\title{
Use of psychoactive substances by young people reporting suicidal thoughts, plans, and attempts in the context of sociodemographic factors
}

\author{
Maciej Zygo', Beata Pawłowska², Emilia Potembska ${ }^{3}$ Lucyna Kapka-Skrzypczak ${ }^{4}$ \\ 'M. Kaczyński Neuropsychiatric Hospital, Lublin, Poland \\ ${ }^{2} 2^{\text {nd }}$ Department of Psychiatry and Psychiatric Rehabilitation, Medical University of Lublin, Poland \\ ${ }^{3}$ Specialist Private Medical Practice, Kolonia Piotrków, Poland \\ ${ }^{4}$ Department of Molecular Biology and Translation Research, Institute of Rural Health, Lublin, Poland
}

\begin{abstract}
Aim of the study: To analyse the prevalence of psychoactive substance use by young people reporting suicidal thoughts, plans, and attempts, including sociodemographic factors.

Material and methods: The study involved 5685 individuals aged 13 to 19 years. Seventy percent ( $n=3980)$ of them were girls and 30\% $(n=1705)$ were boys. They attended schools in the Lublin Province in Eastern Poland. Forty-six percent $(n=2615)$ of those surveyed were city dwellers and 54\% $(n=3070)$ lived in rural areas. The mean age of the participants was 16.91 years and the median was 17 years. The participants were surveyed using a self-report questionnaire designed by the study authors.

Results: Statistically significant relationships were found between the participants' suicidal behaviours (thoughts, plans, and attempts) and their use of alcohol and drugs.

Conclusions: Individuals who report suicidal thoughts, plans, and attempts are more likely to abuse alcohol and use drugs than those who do not report suicidal behaviours. Significantly more young people living in the city than in the countryside abuse alcohol and take drugs. Women who live in urban areas start drinking at a significantly lower age than their peers living in the countryside.
\end{abstract}

KEY WORDS: suicide attempts, adolescents, demographic factors, psychoactive agents.

ADDRESS FOR CORRESPONDENCE: Maciej Zygo, MD, Kaczyński Neuropsychiatric Hospital, 2 Abramowicka St., 20-442 Lublin, Poland, e-mail: zyzio1600@tlen.pl

\section{INTRODUCTION}

Suicide is one of the leading causes of death among adolescents worldwide and the second one among people aged 15-29 years [1,2]. Cantão and Botti [3] demonstrated that among drug addicts the prevalence of suicide is higher than in the wider population. Bridge et al. [4] stressed that the risk of suicide increases in adolescents who use or are addicted to psychoactive agents. Consumption of alcohol and use of drugs by minors have been found to be predictors of suicide attempts. Suicidal behaviour (suicidal ideation and suicide attempts) and substance abuse thus constitute a serious public health problem [4-6]. Gauthier et al. [7] suggest that alcohol abuse is a risk factor for suicidal ideation among jun- ior high school students. Epstein and Spirito [8] and Glasheen et al. [9] demonstrated that alcohol abuse by adolescents correlates not only with suicidal thoughts, but also with suicide plans and attempts. Wu et al. [10] pointed out that people who have made an attempt to take their life are significantly more likely to have taken drugs than those who only report having had suicidal thoughts.

Another predictor of suicidal ideation is early initiation of alcohol use (before the $13^{\text {th }}$ birthday) [11]. Similar results were obtained by Kim and Kim [12], who determined that early initiation of drinking and smoking increases the risk of suicidal thoughts and suicide attempts both in girls and in boys. 
Moreover, the findings of various studies [13-15] have shown that depression is a strong risk factor for other health problems, such as alcohol and other harmful substance use. An important aspect of this problem is also that the comorbidity of depression with drug use may increase the risk for suicide [15], and this constitutes a global public health concern.

\section{AIM OF THE STUDY}

The aim of the study was to analyse the prevalence of psychoactive substance use by young people reporting suicidal thoughts, plans, and attempts, taking into account sociodemographic factors.

\section{MATERIAL AND METHODS \\ PARTICIPANTS}

The study was carried out between December 2013 and April 2014. The participants comprised 5685 individuals aged 13 to 19 years. Seventy percent $(n=3980)$ of them were girls and $30 \%(n=1705)$ were boys. The participants attended schools in the Lublin Province in Eastern Poland. Forty-six percent $(n=2615)$ of those surveyed lived in urban areas and 54\% $(n=3070)$ lived in rural areas. The mean age of the participants was 16.91 years and the median was 17 years.

\section{PROCEDURES}

The survey was conducted in schools whose headteachers had given their consent to the study. An effort was made to survey the largest group of students possible. The study was approved by the Clinical Research Ethics Committee of the Medical University of Lublin and was accepted by the Board of Education. Because participation in the survey was entirely voluntary, not all of the students completed their answer sheets. A total of
6198 questionnaire forms were distributed, 513 of which were rejected as incomplete. All pupils willing to participate in the study filled in the questionnaire during their lessons at school; their anonymity and confidentiality of data were secured.

\section{ETHICAL ISSUES}

The study was approved by the Clinical Research Ethics Committee of the Medical University (number KE-0254/94/2012) and accepted by the Board of Education. On receiving the questionnaires, the participants were informed that they were entitled to receive professional help.

\section{MEASURES}

The participants were surveyed using a self-report questionnaire designed by the study authors, in which the following variables were determined: gender, age, place of residence, educational level, use of drugs, use of designer drugs, alcohol abuse, age of alcohol use initiation, suicidal thoughts and plans, and suicide attempts.

\section{STATISTICAL ANALYSIS}

In order to compare the groups in terms of the selected sociodemographic variables described on a nominal dichotomous scale, a nonparametric $\chi^{2}$ was used. Variables described on an interval scale (age of alcohol initiation) were compared using a $t$-test. A $p$-value of 0.05 was deemed statistically significant. The database and statistical analyses were performed using STATISTICA 10.0. software.

\section{RESULTS}

Table 1 shows the results of the $\chi^{2}$ test, which was used to compare the numbers of participants who did

TABLE 1. Number of young substance abusers reporting suicidal behaviours (thoughts, plans, attempts) by gender

\begin{tabular}{|c|c|c|c|c|c|c|c|c|c|c|}
\hline \multirow{3}{*}{$\begin{array}{l}\text { Variab- } \\
\text { les }\end{array}$} & \multirow[t]{3}{*}{ Gender } & \multicolumn{3}{|c|}{ Suicidal ideation } & \multicolumn{3}{|c|}{ Suicidal plans } & \multicolumn{3}{|c|}{ Suicide attempts } \\
\hline & & No & Yes & \multirow[t]{2}{*}{$\chi^{2}$} & No & Yes & \multirow[t]{2}{*}{$\chi^{2}$} & No & Yes & \multirow[t]{2}{*}{$\chi^{2}$} \\
\hline & & $n(\%)$ & $n(\%)$ & & $n(\%)$ & $n(\%)$ & & $n(\%)$ & $n(\%)$ & \\
\hline \multirow[t]{3}{*}{$\begin{array}{l}\text { Binge } \\
\text { drinking }\end{array}$} & $\begin{array}{l}\text { Entire } \\
\text { group }\end{array}$ & $\begin{array}{c}1654 \\
(39.29)\end{array}$ & $\begin{array}{c}776 \\
(56.56)\end{array}$ & $125.58^{* * *}$ & $\begin{array}{c}1905 \\
(40.60)\end{array}$ & $\begin{array}{c}517 \\
(59.49)\end{array}$ & $106.45^{* * *}$ & $\begin{array}{c}2255 \\
(42.34)\end{array}$ & $\begin{array}{c}167 \\
(66.80)\end{array}$ & $58.15^{* * *}$ \\
\hline & Female & $\begin{array}{c}804 \\
(31.69)\end{array}$ & $\begin{array}{c}548 \\
(54.31) \\
\end{array}$ & $156.58^{* * *}$ & $\begin{array}{c}979 \\
(33.79)\end{array}$ & $\begin{array}{c}370 \\
(57.90) \\
\end{array}$ & $128.97^{* * *}$ & $\begin{array}{c}1227 \\
(36.49)\end{array}$ & $\begin{array}{c}125 \\
(65.79) \\
\end{array}$ & $65.51^{* * *}$ \\
\hline & Male & $\begin{array}{c}675 \\
(51.76) \\
\end{array}$ & $\begin{array}{c}154 \\
(64.17) \\
\end{array}$ & $12.54^{* * * *}$ & $\begin{array}{c}728 \\
(52.49) \\
\end{array}$ & $\begin{array}{c}96 \\
(64.86) \\
\end{array}$ & $8.24^{* *}$ & $\begin{array}{c}800 \\
(53.30)\end{array}$ & $\begin{array}{c}23 \\
(69.70) \\
\end{array}$ & 3.49 \\
\hline \multirow[t]{3}{*}{ Drugs } & $\begin{array}{l}\text { Entire } \\
\text { group }\end{array}$ & $\begin{array}{c}538 \\
(17.64)\end{array}$ & $\begin{array}{c}359 \\
(32.20) \\
\end{array}$ & $102.40^{* * *}$ & $\begin{array}{c}640 \\
(18.61)\end{array}$ & $\begin{array}{c}254 \\
(35.83) \\
\end{array}$ & $103.03^{* * *}$ & $\begin{array}{c}797 \\
(20.15)\end{array}$ & $\begin{array}{c}96 \\
(46.83)\end{array}$ & $82.28^{* * *}$ \\
\hline & Female & $\begin{array}{c}226 \\
(12.23)\end{array}$ & $\begin{array}{c}228 \\
(27.98) \\
\end{array}$ & $99.16^{* * *}$ & $\begin{array}{c}292 \\
(13.66)\end{array}$ & $\begin{array}{c}160 \\
(31.01) \\
\end{array}$ & $88.45^{* * *}$ & $\begin{array}{c}383 \\
(15.27)\end{array}$ & $\begin{array}{c}70 \\
(44.87) \\
\end{array}$ & $91.18^{* * * *}$ \\
\hline & Male & $\begin{array}{c}247 \\
(26.62)\end{array}$ & $\begin{array}{c}91 \\
(45.27)\end{array}$ & $27.42^{* * *}$ & $\begin{array}{c}275 \\
(27.56)\end{array}$ & $\begin{array}{c}62 \\
(50.00)\end{array}$ & $26.44^{* * *}$ & $\begin{array}{c}324 \\
(29.45)\end{array}$ & $\begin{array}{c}11 \\
(45.83)\end{array}$ & 3.01 \\
\hline
\end{tabular}

${ }^{*} p<0.05,{ }^{* *} p<0.01,{ }^{* * * *} p<0.001$ 
TABLE 2. Numbers of suicidal substance abusers by place of residence (urban vs rural)

\begin{tabular}{|c|c|c|c|c|c|c|c|c|c|c|}
\hline \multirow[t]{3}{*}{ Variables } & \multirow[t]{3}{*}{ Gender } & \multicolumn{3}{|c|}{ Suicidal ideation } & \multicolumn{3}{|c|}{ Suicidal plans } & \multicolumn{3}{|c|}{ Suicide attempts } \\
\hline & & \multirow{2}{*}{$\frac{\text { Urban }}{n(\%)}$} & \multirow{2}{*}{$\frac{\text { Rural }}{n(\%)}$} & \multirow[t]{2}{*}{$\chi^{2}$} & Urban & Rural & \multirow[t]{2}{*}{$\chi^{2}$} & Urban & Rural & \multirow[t]{2}{*}{$\chi^{2}$} \\
\hline & & & & & $n(\%)$ & $n(\%)$ & & $n(\%)$ & $n(\%)$ & \\
\hline \multirow[t]{3}{*}{$\begin{array}{l}\text { Binge } \\
\text { drinking }\end{array}$} & $\begin{array}{l}\text { Entire } \\
\text { group }\end{array}$ & $\begin{array}{c}355 \\
(56.08)\end{array}$ & $\begin{array}{c}396 \\
(57.56)\end{array}$ & 0.29 & $\begin{array}{c}226 \\
(58.85)\end{array}$ & $\begin{array}{c}270 \\
(60.27)\end{array}$ & 0.17 & $\begin{array}{c}96 \\
(75.59)\end{array}$ & $\begin{array}{c}67 \\
(58.77)\end{array}$ & $7.76^{* *}$ \\
\hline & Female & $\begin{array}{c}243 \\
(54.12)\end{array}$ & $\begin{array}{c}291 \\
(54.70)\end{array}$ & 0.03 & $\begin{array}{c}155 \\
(57.84)\end{array}$ & $\begin{array}{c}203 \\
(58.17)\end{array}$ & 0.01 & $\begin{array}{c}68 \\
(74.73)\end{array}$ & $\begin{array}{c}53 \\
(56.38)\end{array}$ & $6.88^{* *}$ \\
\hline & Male & $\begin{array}{c}73 \\
(59.35) \\
\end{array}$ & $\begin{array}{c}75 \\
(68.81) \\
\end{array}$ & 2.24 & $\begin{array}{c}46 \\
(60.53)\end{array}$ & $\begin{array}{c}45 \\
(69.23) \\
\end{array}$ & 1.16 & $\begin{array}{c}14 \\
(70.00)\end{array}$ & $\begin{array}{c}9 \\
(75.00)\end{array}$ & 0.09 \\
\hline \multirow[t]{3}{*}{ Drugs } & $\begin{array}{l}\text { Entire } \\
\text { group }\end{array}$ & $\begin{array}{c}198 \\
(36.80)\end{array}$ & $\begin{array}{c}145 \\
(27.05)\end{array}$ & $11.74^{* * *}$ & $\begin{array}{c}136 \\
(41.59)\end{array}$ & $\begin{array}{c}103 \\
(29.26)\end{array}$ & $11.30^{* * * *}$ & $\begin{array}{c}59 \\
(53.64)\end{array}$ & $\begin{array}{c}35 \\
(39.33)\end{array}$ & $4.04^{*}$ \\
\hline & Female & $\begin{array}{c}125 \\
(32.98)\end{array}$ & $\begin{array}{c}95 \\
(22.95)\end{array}$ & $9.94^{* *}$ & $\begin{array}{c}88 \\
(38.43)\end{array}$ & $\begin{array}{c}65 \\
(23.99)\end{array}$ & $12.19^{* * * *}$ & $\begin{array}{c}43 \\
(53.09)\end{array}$ & $\begin{array}{c}25 \\
(34.25)\end{array}$ & $5.53^{*}$ \\
\hline & Male & $\begin{array}{c}49 \\
(46.67)\end{array}$ & $\begin{array}{c}37 \\
(42.05)\end{array}$ & 0.41 & $\begin{array}{c}29 \\
(47.54)\end{array}$ & $\begin{array}{c}28 \\
(50.00)\end{array}$ & 0.07 & $\begin{array}{c}6 \\
(46.15)\end{array}$ & $\begin{array}{c}5 \\
(50.00)\end{array}$ & 0.03 \\
\hline
\end{tabular}

${ }^{*} p<0.05,{ }^{* * *} p<0.01,{ }^{* * *} p<0.001$

TABLE 3. Comparison of age of alcohol initiation between city and country dwellers who report suicidal behaviour

\begin{tabular}{|c|c|c|c|c|c|c|c|c|c|c|}
\hline \multirow[t]{3}{*}{ Gender } & \multirow[t]{3}{*}{ Variables } & \multicolumn{3}{|c|}{ Suicidal ideation } & \multicolumn{3}{|c|}{ Suicidal plans } & \multicolumn{3}{|c|}{ Suicide attempts } \\
\hline & & Urban & Rural & $t$ & Urban & Rural & $t$ & Urban & Rural & $t$ \\
\hline & & $M(S D)$ & $\mathrm{M}(\mathrm{SD})$ & & $\mathrm{M}(\mathrm{SD})$ & $\mathrm{M}(\mathrm{SD})$ & & $\mathrm{M}(\mathrm{SD})$ & $\mathrm{M}(\mathrm{SD})$ & \\
\hline $\begin{array}{l}\text { Entire } \\
\text { group }\end{array}$ & $\begin{array}{c}\text { Age of alcohol } \\
\text { initiation }\end{array}$ & $\begin{array}{l}14.09 \\
(1.71)\end{array}$ & $\begin{array}{l}14.48 \\
1.65)\end{array}$ & $-3.66^{* * *}$ & $\begin{array}{l}14.07 \\
(1.76)\end{array}$ & $\begin{array}{l}14.39 \\
(1.69)\end{array}$ & $-2.31^{*}$ & $\begin{array}{l}13.69 \\
(1.76)\end{array}$ & $\begin{array}{l}14.30 \\
(1.70)\end{array}$ & $-2.39^{*}$ \\
\hline Female & $\begin{array}{c}\text { Age of alcohol } \\
\text { initiation }\end{array}$ & $\begin{array}{l}14.10 \\
(1.63) \\
\end{array}$ & $\begin{array}{l}14.59 \\
(1.59) \\
\end{array}$ & $-4.11^{* * *}$ & $\begin{array}{l}14.08 \\
(1.69) \\
\end{array}$ & $\begin{array}{l}14.51 \\
(1.63) \\
\end{array}$ & $-2.77^{* *}$ & $\begin{array}{l}13.77 \\
(1.77) \\
\end{array}$ & $\begin{array}{l}14.39 \\
(1.65) \\
\end{array}$ & $-2.13^{*}$ \\
\hline Male & $\begin{array}{l}\text { Age of alcohol } \\
\text { initiation }\end{array}$ & $\begin{array}{l}14.11 \\
(1.69)\end{array}$ & $\begin{array}{l}13.94 \\
(1.76)\end{array}$ & 0.62 & $\begin{array}{l}13.94 \\
(1.81)\end{array}$ & $\begin{array}{l}13.65 \\
(1.81)\end{array}$ & 0.81 & $\begin{array}{l}13.50 \\
(1.51)\end{array}$ & $\begin{array}{l}13.50 \\
(1.31)\end{array}$ & 0.01 \\
\hline
\end{tabular}

and did not report suicidal behaviour in relation to the use of psychoactive agents.

Compared to their non-suicidal peers, young people, both female and male, who reported suicidal thoughts and plans, more often reported having abused alcohol and used drugs. Significantly more young people, mainly men attempting suicide, binge drink and take drugs.

Table 2 shows the results of the $\chi^{2}$ test, which was used to compare the numbers of young people who reported suicidal behaviours and used psychoactive agents, in relation to their place of residence (urban/rural).

Female suicide attempters who lived in a city were more likely to abuse alcohol (engage in binge drinking) and use drugs than those who lived in the countryside. Among females who reported suicidal thoughts and plans, city dwellers were significantly more likely than country dwellers to use drugs. Table 3 shows the results of Student's $t$-test comparing the age of alcohol initiation between suicidal youngsters living in urban vs. rural areas.
Women who lived in urban areas had started drinking at a significantly lower age than their peers living in the countryside.

\section{DISCUSSION}

The statistical results show that young people who reported suicidal thoughts and plans and suicide attempts were significantly more likely to abuse alcohol and drugs than their non-suicidal peers. It should be noted that more than half of the respondents reporting suicidal behaviour abused alcohol: $56.56 \%$ of people reporting suicidal thoughts, $59.49 \%$ reporting suicide plans, and $66.80 \%$ reporting attempting suicide.

These findings are consistent with the results of previous research, which draws attention to significant relationships between suicidal behaviours in adolescents and young adults and the use of psychoactive agents [6, 16-19]. Miller et al. [20] emphasised that people who abuse alcohol and use drugs are more likely to report suicidal thoughts and plans than those who do not use psychoactive sub- 
stances. These findings also confirmed the results of other studies $[2,3,6]$. The relationship is so strong that the use of alcohol and drugs are considered predictors of suicide attempts by minors [21]. Peltzer and Pengpid [22] found in a study of a cohort of 13-16-year-olds that suicidal ideation precedes the use of psychoactive substances. Spirito et al. [23] and Hufford [24] found that suicide attempts co-occurred with substance abuse. According to Gauthier et al. [7], alcohol abuse is a risk factor for suicidal ideation in this group of people. Such results also appeared in the latest international studies [15, 19, 25-27].

The results of the statistical analyses indicate that both females and males who report suicidal thoughts and plans and suicide attempts start drinking at a younger age than young people who do not show such behaviours. In the group of people who engage in suicidal behaviours, city dwellers initiate alcohol use at a younger age than do adolescents living in the countryside. These results are consistent with the findings of Swahn et al. [28] and Kim and Kim [12], who emphasised that early alcohol initiation is associated with suicide attempts by young people.

The results presented above not only have theoretical merit but are also of practical interest. Different scientists $[15,20]$ have concluded that efforts to reduce the use and abuse of alcohol and drugs may reduce the risk of ensuing suicidal behaviour among adolescents. The results of this study can be used as leads for therapists and prevention workers to plan therapeutic and preventive impacts.

Because many studies consider the impact of psychoactive substance use on depressive symptoms and its impact on suicidal behaviours, it might be also interesting to verify which variables are the most important to reduce the risk of suicide in the group of young people. It could be the base of the next study in this field.

\section{CONCLUSIONS}

Individuals who report suicidal thoughts, plans, and suicide attempts are more likely to abuse alcohol and use drugs than those who do not report suicidal behaviours.

Significantly more young people living in the city than in the countryside abuse alcohol and take drugs.

Females who live in urban areas start drinking at a significantly lower age than their peers living in the countryside.

\section{DISCLOSURE}

The authors report no conflict of interest.

\section{References}

1. World Health Organization. Preventing suicide: a global imperative. World Health Organization, Geneva 2014.

2. Simbar M, Golezar S, Alizadeh Sh, Hajifoghaha M. Suicide Risk Factors in Adolescents Worldwide: A Narrative Review. J Rafsanjan Univ Med Sci 2018; 16 (12): 1153-1168.
3. Cantão L, Botti NC. Suicidal behavior among drug addicts. Rev Bras Enferm 2016; 69 (2): 389-396.

4. Bridge JA, Goldstein TR, Brent DA. Adolescent suicide and suicidal behavior. J Child Psychol Psychiatry 2006; 47 (3-4): 372-394.

5. World Health Organization. The health and social effects of nonmedical cannabis use, 2016. World Health Organization, Geneva 2016.

6. Pereira-Morales AJ, Adan A, Camargo A, Forero DA. Substance use and suicide risk in a sample of young Colombian adults: An exploration of psychosocial factors. Am J Addict 2018; 26: 388-394.

7. Gauthier JM, Witte TK, Correia CJ. Suicide ideation, alcohol consumption, motives, and related problems: exploring the association in college students. Suicide Life Threat Behav 2017; 47 (2): 142-154.

8. Epstein JA, Spirito A. Risk factors for suicidality among a nationally representative sample of high school students. Suicide Life Threat Behav 2009; 39 (3): 241-251.

9. Glasheen C, Pemberton MR, Lipari R, et al. Binge drinking and the risk of suicidal thoughts, plans, and attempts. Addict Behav 2015; 43: 42-49.

10. Wu P, Hoven CW, Liu X, et al. Substance use, suicidal ideation and attempts in children and adolescents. Suicide Life Threat Behav 2004; 34 (4): 408-420.

11. Pompili M, Serafini G, Innamorati M, et al. Suicidal behavior and alcohol abuse. Int J Environ Res Public Health 2010; 7 (4): 1392-1431.

12. Kim DS, Kim HS. Early initiation of alcohol drinking, cigarette smoking, and sexual intercourse linked to suicidal ideation and attempts: findings from the 2006 Korean Youth Risk Behavior Survey. Yonsei Med J 2010; 51 (1): 18-26.

13. Silva ER, Sousa ARP, Ferreira LB, Peixoto HM. Prevalence and factors associated with depression among institutionalized elderly individuals: Nursing care support. Rev Esc Enferm USP 2012; 46 (6): 1387-1393.

14. Ipsos, National Institute of Public Policy for Alcohol and Other Drugs (INPAD). Brazil National Alcohol and Drugs Survey 2011-2012. University of São Paulo, Brazil.

15. Fontanella CA, Warner LA, Hiance-Steelesmith DL, et al. Service use in the month and year prior to suicide among adults enrolled in Ohio Medicaid. Psychiatr Serv 2017; 68 (7): 674-680.

16. Ferrari AJ, Norman RE, Freedman G, et al. The burden attributable to mental and substance use disorders as risk factors for suicide: findings from the Global Burden of Disease Study 2010. PLoS One 2014; 9 (4): e91936.

17. Darvishi N, Farhadi M, Haghtalab T, et al. Alcohol-related risk of suicidal ideation, suicide attempt, and completed suicide: a meta-analysis. PLoS One 2015; 10 (5): e0126870.

18. Shalit N, Shoval G, Shlosberg D, et al. The association between cannabis use and suicidality among men and women: a population based longitudinal study. J Affect Disord 2016; 205: 216-224.

19. Guedria-Tekari A, Missaoui S, Kalai W, et al. Suicidal ideation and suicide attempts among Tunisian adolescents: prevalence and associated factors. Pan Afr Med J 2019; 34: 105. 
20. Miller M, Borges G, Orozco R, et al. Exposure to alcohol, drugs and tobacco and the risk of subsequent suicidality: Findings from the Mexican Adolescent Mental Health Survey. Drug Alcohol Depend 2011; 113 (2-3): 110-117.

21. Arenliu A, Kelmendi K, Haskuka M, et al. Drug use and reported suicide ideation and attempt among Kosovar adolescents. J Subst Use 2014; 19 (5): 358-363.

22. Peltzer K, Pengpid S. Early substance use initiation and suicide ideation and attempts among school-aged adolescents in four Pacific Island Countries in Oceania. Int J Environ Res Public Health 2015; 12 (10): 12291-12303.

23. Spirito A, Mehlenbeck R, Barnett N, et al. The relation of mood and behavior to alcohol use in adolescent suicide attempters. J Child Adolesc Subst Abuse 2003; 12 (4): 35-53.

24. Hufford MR. Alcohol and suicidal behavior. Clin Psychol Rev 2001; 21 (5): 797-811.

25. Brincoveanu AM, Suciu O, Hogea LM, et al. Study of some psychoactive drugs and their role in increasing the risk of suicide. Revista De Chimie 2019; 70 (4): 1399-1402.

26. Birhanu A, Mekuria M. Prevalence of Alcohol Use Disorders and Associated Factors among Ambo Town Community, Central Ethiopia: A Community Based Cross-Sectional Study. J Addict Res Ther 2019; 10 (4): 1000389.

27. Valdez-Santiago R, Solorzano EH, Iniguez MM, et al. Attempted suicide among adolescents in Mexico: prevalence and associated factors at the national level. Inj Prev 2018; 24 (4): 256-261.

28. Swahn MH, Bossarte RM, Sullivent EE. Age of alcohol use initiation, suicidal behavior, and peer and dating violence victimization and perpetration among high-risk, seventh-grade adolescents. Pediatrics 2008; 121 (2): 297-305.

\section{AUTHORS' CONTRIBUTIONS}

MZ prepared research concept and design of the publication, collected data, analysed them and wrote the article. BP, EP, LKS critically revised it. All authors contributed to preparing the final publication. 